\title{
A ROUPA EXPRESSA A IDENTIDADE: MODA ENQUANTO TECNOLOGIA DE GÊNERO NA EXPERIÊNCIA TRANSGÊNERO
}

Isabel Wittmann

Universidade de São Paulo, São Paulo, Brasil ${ }^{1}$

\begin{abstract}
Esse artigo visa explorar a noção de moda enquanto tecnologia de gênero: capaz, por vias discursivas ou práticas, de criar o próprio gênero. Por meio de relatos que partem de experiência transgênero discuto a forma como as roupas codificam significados, que passam pela própria expressão de feminilidades e masculinidades. Questiono, por outro lado, a própria noção do que seria uma moda feminina ou uma masculina, já que elas são agenciadas conforme a necessidade de expressão das subjetividades, negociando corpos e identidades. Apresento os conflitos revelados entre essas subjetividades e as normativas que envolvem o vestuário, especialmente quando se trata de familia e escola, dois agentes de normalização relevantes. Por fim, destaco que as narrativas, em sua pluralidade, não devem ser lidas como uma expressão monolitica da experiência transgênero, mas como uma mostra da relação entre performatividade e moda.
\end{abstract}

Palavras-chave: transgeneridade, tecnologia de gênero, moda, performatividade

A etnografia aqui apresentada nasceu do desejo de me inserir no campo de estudos de gênero, ao mesmo tempo em que se delineou por meio do interesse pela moda como objeto de estudo. Sua gênese partiu do interesse em pesquisar a relação entre a performatividade de gênero e a moda, enquanto ferramenta utilizada para expressá-la. O objetivo era entender como pessoas com identidades transgênero, ou seja, que não se identificam com o gênero que lhes foi atribuído ao nascer, se relacionavam com a moda. O trabalho de campo foi realizado entre janeiro de 2013 e fevereiro de $2016 .^{2}$

1 Contato da autora: iwittmann@gmail.com.

2 Artigo baseado na dissertação Corpo, Gênero e Identidade: experiências transgênero na cidade de Manaus, desenvolvida pela autora, defendida em 2016 sob orientação da Profa Dra. Márcia Regina Calderipe Farias Rufino e co-orientação da Profa Dra. Fátima Weiss de Jesus, no Programa de Pós-Graduação em Antropologia Social da Universidade Federal do Amazonas (PPGAS-UFAM), com recursos de bolsa de pesquisa provida pela FAPEAM. 
Boa parte dos dados vieram da internet, já que muitas das pessoas que colaboraram com meu trabalho demonstraram receio de nos encontrarmos pessoalmente. A exceção foram dois interlocutores que optaram por se encontrar comigo juntos e presencialmente. Esse contato coloca a pesquisa em ambiente virtual como uma possibilidade de abordagem etnográfica, já que abre portas para novas formas de interação, uma vez que o etnógrafo se posiciona no ciberespaço, entendido "como espaço simbólico, de comunicação, interação e sociabilidade" (Parreiras, 2009: 344). Embora o ciberespaço não fosse, originalmente, o local de campo pretendido, essa adaptação se mostrou, afinal, bastante proveitosa, pois as interações nas redes sociais se tornaram constantes, quase diárias. $\mathrm{O}$ campo se abriu para novas textualidades. Os espaços que mais utilizei foram a rede social Facebook e o aplicativo Whatsapp. ${ }^{3}$

Os dados foram obtidos a partir das conversas ocorridas durante o período de campo. O dado mais importante, claro, é aquele da auto-identificação de identidade de gênero, que demonstra a variedade de formas de expressão de identidade. Os demais dados criam um panorama em que é possível entendê-los por meio de uma perspectiva interseccional (Crenshaw, 2002). Pode-se dizer que todas são pessoas pertencentes a camadas médias urbanas, com acesso à educação, sendo que em alguns casos o ensino está em andamento e em outros tratam-se de profissionais já com formação. Esse dado é importante porque é um recorte bastante específico da pesquisa. É claro que nem todas as pessoas transgênero pertencem às classes médias, mas talvez isso se deva ao contato predominantemente feito por meio da internet e à facilidade desse acesso por pessoas dessa camada social. Desse modo, o contexto da pesquisa em classes médias urbanas traz na fala das interlocutoras e interlocutores valores a elas relacionados, que se somam ao conjunto das pesquisas já existentes que trazem relatos de experiências transgêneros.

Parto da conexão da moda com o próprio gênero e a performatividade. Para Teresa de Lauretis, gênero é "produto de várias tecnologias sociais", assim como "de discursos institucionalizados, epistemologias e práticas críticas, bem como práticas cotidianas” (Lauretis, 1987: 2, tradução minha). Além disso utilizo a ideia de "experiência transgênero", discutida por Sônia Maluf, que a define como sendo:

um conjunto de práticas diversificadas que envolvem não apenas o cross-dressing, como a vivência subjetiva de tornar-se outro, que implica a transcendência da identidade como noção central na discussão sobre a constituição do sujeito e o reconhecimento da "dimensão alteritária" como central para esses sujeitos (Maluf, 2001: 100).

Segundo Lauretis, a experiência pode ser entendida como o processo pelo qual "a subjetividade é construída", ou ainda como efeito de "significado, hábitos, disposições, associações e percepções resultantes da interação semiótica do eu e do mundo exterior” (Lauretis, 1987: 18). Essa interação do eu com o mundo exterior dialoga com a construção do sujeito mencionada por Sonia Maluf (2001), uma vez que é nessa relação de alteridade com as normas que se projeta a identidade.

Por sua vez, falando a respeito da experiência como origem de informação para quem pesquisa, Joan Scott afirma que ela é a fonte do conhecimento, proveniente da visão individual sobre o qual ele se constrói. Scott traz a experiência para o campo do conhecimento, em que o fato ou o relato partem das referências que as próprias pessoas envolvidas têm (Scott, 2001). Levo em conta o entendimento de Lauretis a respeito da experiência, também individual, como

3 Aplicativo de celular que permite troca instantânea e gratuita de mensagens. 
um processo de formação da subjetividade por intermédio das relações com o mundo, que enriquecem as trajetórias e criam conhecimento e memórias (Lauretis, 1987: 18). Portanto a experiência pode ser entendida, conforme Simone Ávila, como um evento "que não ocorre fora de significados estabelecidos, mas tampouco está confinada a uma ordem fixa de significado" (Ávila, 2014: 36). Dessa maneira, é possível aplicar ambas as reflexões e usar o relato de experiência como a verdade e a evidência para essa pesquisa etnográfica, justificando, dessa forma, o uso do termo "experiência transgênero".

Os trabalhos de Berenice Bento $(2004 ; 2006 ; 2009)$ a respeito de transexualidade, de Anna Paula Vencato $(2003 ; 2005 ; 2013)$ sobre drag queens ${ }^{4}$ e crossdressers, ${ }^{5}$ bem como de Sonia Maluf (2001; 2002; 2007), abordando aspectos sobre corpo e gênero foram essenciais para a percepção das diversas identidades transgênero. Vencato, em especial, aborda de maneira aprofundada questões relacionadas à "montaria", que consiste na incorporação de roupas, maquiagem, maneira de se portar e falar, no caso específico da composição das personagens das drag queens (Vencato, 2005). A moda aparece nas falas das interlocutoras e dos interlocutores, marcando a reflexão que fazem sobre suas experiências.

\section{MODA, IDENTIDADE E EXPRESSÃO DA SUBJETIVIDADE}

Conforme Gilles Lipovetsky, a moda é marcada pela "metamorfose dos estilos e dos ritmos precipitados da mudança no vestir" (Lipovetsky, 2009: 25), de forma que ela pode ser entendida como um sistema de produção que cria formas e modos de vestir e que só é possível no contexto do que chama de "mundo moderno ocidental" (Lipovetsky, 2009: 24). Ao mesmo tempo que está vinculada à produção em escala industrial, à mídia e à publicidade, a moda é inerentemente vinculada à noção de indivíduo. Conforme o autor, "A moda como sistema é inseparável do 'individualismo' - em outras palavras, de uma relativa liberdade deixada às pessoas para rejeitar, modular ou aceitar as novidades do dia" (Lipovetsky, 2009: 47).

De acordo com Laura Bovone e Diane Crane, a moda "pode ser conceitualizada como um exemplo de um fenômeno maior, a criação e a atribuição de valores simbólicos à cultura material" (Crane; Bovone, 2006: 320, tradução minha). Dessa forma, as roupas envolvidas nesses processos não apenas refletem um padrão de consumo, ${ }^{6}$ mas também são responsáveis pela criação e manutenção de uma série de signos dentro do contexto em que são inseridas, como a representação de identidade, não só de gênero, mas de grupo, de classe social, entre outras.

É, portanto, por meio do individualismo, ou ainda da subjetividade dos sujeitos, que a moda é filtrada para os modos de vestir, citados por Lipovetsky, resultando na criação dos significados identitários. A vestimenta, assim, estabelece categorias de sujeitos (Santos, 1997), uma

4 As drag queens são artistas que se "montam" para performance e cujo objetivo final não necessariamente é ficar parecidas com mulheres (Vencato, 2003: 198). Elas se diferenciam das demais identidades transgênero em virtude da transitoriedade de suas montagens.

5 Pessoas que utilizam roupas e acessórios que são comumente vinculados ao gênero aposto àquele que thes foi designado ao nascer. Geralmente são homens que se vestem como mulheres, mas não se veem como tal (Vencato, 2013: 32-33).

6 De acordo com Blumer (2005: 278) mais do que ser ditada por uma busca de diferenciação social, como escreve Simmel (2008), a moda se perpetua através de um processo coletivo de seleção, que passa pelos produtores e pelos compradores e tem critérios subjetivos, como apelo estético e conformação com um senso de modernidade. 
vez que ela é facilmente lida e codificada com signos que determinam e limitam tais categorias. $\mathrm{O}$ vestir, por sua vez, pode ser entendido como

meios de falar de si (a seu modo autobiográfico), mas também de agenciar/inventar outros "si", desconhecidos em nós. Os atos que envolvem o vestir compõem, nesta perspectiva, essa dimensão subjetiva onde convivem dilemas contemporâneos, como aqueles vividos pelos corpos em suas múltiplas possibilidades de reconfiguração (Portela; Brandão, 2008: 61).

Dessa forma, esse artigo não aborda a moda no sentido estrito de sucessão de estilos marcada pelo tempo e pelo espaço. Aqui trata-se da moda modulada pelos sujeitos, perpassada pela noção de individualidade e subjetividade, resultando no vestir, que constrói narrativas sobre eles e sobre seus corpos, marcados por identidades.

Para Lars Svendsen, "identidade" seria mesmo "um dos conceitos seminais para se descrever a função da moda" (Svendsen, 2010: 158). Nesse sentido, Ann Mari Sellerberg desenvolve que se pode dizer que a moda aparece, portanto, com as funções simbólicas de marcar diferenças e de expressar comunidade, dois critérios fundamentais quando se refere à identidade (Sellerberg, 2001). Essas funções têm papel importante quando se trata de identidade de gênero, em específico, já que é por meio tanto das roupas como dos acessórios que se estabelecem uma as primeiras etapas do "reconhecimento social" (Vencato, 2005: 235).

Thomas, ${ }^{7}$ um nutricionista de 27 anos que se identifica como homem trans, se expressa, nesse sentido, afirmando que "a gente precisa da roupa pra dizer quem a gente é sem palavras, sem precisar de palavras", ou seja, que o vestuário exprime uma mensagem fácil e direta a respeito da identidade de gênero, uma vez que ele é filtrado pelo conhecimento pré-existente das pessoas de um determinado local sobre os códigos vigentes. Já para Leonardo, estudante universitário de 22 anos, também identificado como homem trans, o reforço do já existente pode ter efeitos negativos:

Mas aí eu tava pensando se a gente não reforça esses estereótipos, porque, tipo, ah, eu era uma mulher magra, quero ser um homem trans bombado. Então vou seguir o estereótipo de que homem tem que ser fortinho. O homem não pode ser magro? Ter o cabelo grande? A gente acaba reforçando alguns estereótipos, por necessidade, até (Leonardo).

Thomas e Leonardo marcam, portanto, a maneira codificada como a moda é utilizada, negociando o espaço do reconhecimento e da reafirmação de estereótipo. Umberto Eco discorre justamente sobre as vestimentas enquanto códigos, com valores e significados específicos a serem compreendidos no contexto sociocultural, e que poderiam ser entendidas como uma forma de comunicar algo sobre a pessoa que as utiliza:

É claro que a roupa serve principalmente para nos cobrirmos com ela. Mas basta fazer uma autoanálise honesta, mesmo breve, para verificarmos que, no nosso vestuário, o que serve realmente para cobrir (para proteger do calor ou do frio e para a ocultar a nudez que a opinião pública considera vergonhosa) não supera os cinquenta por cento do conjunto. [...] O vestuário é comunicação (Eco, 1989: 7).

Por outro lado, é preciso entender que essa comunicação não se estabelece como uma linguagem, uma vez que para tanto deveria trazer termos precisos que podem ser compreendidos certamente dentro do contexto empregado, o que não acontece com o vestuário:

7 Em virtude do temor do reconhecimento por parte de algumas interlocutoras, tomei o cuidado ético de usar nomes fictícios em todo o corpo do trabalho (Ávila, 2014: 54). 
os códigos do vestuário existem, embora muitas vezes sejam fracos. Mas fracos quer dizer que mudam com uma certa rapidez, pelo que é difícil estender até eles os respectivos "dicionários" e o código é frequentemente reconstruído no momento, na situação dada, sendo inferido a partir das próprias mensagens (Eco, 1989: 18).

Por isso, embora tenha um conjunto de significados que podem ser lidos, a moda não pode ser entendida como uma linguagem propriamente dita, já que a forma como seus signos são interpretados é constantemente alterada. De acordo com Daniel Miller, o problema de interpretar a roupa como uma mera linguagem é que isso a coloca como refém dos humanos, esvaziando-a de valor e colocando-a no papel de "simples trecos inanimados" (Miller, 2013: 22).

O antropólogo explica que o fato de a cultura ocidental entender a roupa como uma expressão externa, oposta a um verdadeiro eu interno, faz com que tenhamos a percepção de que pessoas que se preocupam com a aparência são superficiais. Citando seu trabalho de campo em Trinidad, afirma que a população local está longe de ter a mesma ideia: para eles a verdade da subjetividade do sujeito está na superfície e é aquilo que pode ser facilmente apreendido, uma vez que é no interior que escondemos tudo aquilo que não queremos que os outros saibam. Por isso, os trinitários têm grande preocupação com suas roupas, não as repetem em ocasiões especiais e as desfilam orgulhosamente na rua. O que importa não é que uma tendência seja seguida ou o que é vestido, mas o "estilo", ou como é vestido (Miller, 2013).

Mas se para os trinitários a roupa é uma expressão de nosso exterior, ou seja, da verdade do sujeito e não de nosso interior, essa percepção passa longe do entendimento que encontramos em nossa própria sociedade, em que o interior é entendido como o local da subjetividade. Sara, programadora de 40 anos que se define como crossdresser, ao ser perguntada sobre sentimentos que nutre em relação à moda, fala de um eu interior que pode se expressar quando está montada:

Meu sentimento [a respeito de suas roupas] é uma mistura de harmonia e encantamento. As roupas tornam o meu Eu interior mais harmônico com o meu Eu exterior e fico absolutamente encantada com a beleza do mundo que fica a minha volta quando estou montada (Sara).

Essa harmonia, segundo sua fala, faz parte desse sentido de externar quem se é de verdade, expressado por Miller (2013), alinhando o sentimento subjetivo que tem ao seu próprio respeito com a aparência que passa a apresentar. Mas a prática do crossdressing não é uma constante. De acordo com ela, ao longo do tempo teve várias urges e purges $^{8}$ e já chegou a ter o guarda-roupa composto por $70 \%$ de roupas femininas. No momento de nossas primeiras conversas, estava saindo de uma purge e, portanto, com o repertório de trajes entendidos como femininos reduzido. Relatou que suas purges são leves, mas que ainda assim doa uma boa parte de suas roupas, ficando só com aquelas com que tem algum tipo de ligação. Segundo ela, as urges podem ser bem longas, mas as purges duram cerca de dois a três meses. A ligação com suas roupas é facilmente percebida em sua fala, na sequência da mesma pergunta:

A minha ligação [com a moda] é enorme pois a minha realização feminina é exatamente através do uso do meu vestuário. Sigo um verdadeiro ritual quando me monto. Nesse ritual está incluída a depilação (que, no meu caso, precisa ser frequente), a make e por fim o uso propriamente de vestidos, saias, shorts, blusas, calças, sapatos e os acessórios. O sentimento principal que tenho por algumas é de apego completo por representarem datas, eventos e acontecimentos que marcaram minha vida. O detalhe é que algumas não cabem mais em mim. aí ficam apenas guardadas mesmo (Sara).

$8 \quad$ Urge é o período de intensificação do processo de montagem e purge é o período de negação e afastamento do mesmo (Vencato, 2013: 23). 
Sara toma objetos como símbolos de momentos importantes. Nesse caso, as próprias roupas ocupam esse papel, mesmo que não sirvam mais. Esses momentos também podem estar ligados a datas especiais. Em uma conversa, Sara se referiu ao desejo de usar um vestido em sua formatura que se aproximava. Mas como nem todos sabem sobre sua prática do crossdressing, decidiu tirar fotos com o vestido somente depois da cerimônia, à guisa de satisfação de sua vontade.

Imagina meu vestido. Eu vi naquela loja do Vieiralves, azul claro de cetim com detalhes no busto e costas de rendinha e tule. Elas [as vendedoras] sabiam, tiraram medidas e tudo. Disseram pra eu caprichar na malhação, pra fazer cinturinha. Foi semana passada. Passei o fim de semana sonhando com ele. Não quero forçar. Vou fazer fotos depois de formada para guardar (Sara).

É fácil notar como o rito de passagem que marca a formatura aparece quase que materializado na ideia do vestido que o representa, compartilhado como um segredo apenas com as vendedoras da loja. São as amarras sociais que impedem Sara de expressar seu desejo. Mas o processo de montaria não consiste somente das peças de vestuário: acessórios, maquiagem e mesmo intervenções cosméticas no corpo ajudam a construir a imagem desejada. Porém, ela afirma que o vestuário atende apenas a necessidade de uma expressão visual para ela e outras pessoas, porque sua identidade de gênero "gera muitas expectativas e a maior parte não é visual":

[as roupas] ajudam essencialmente a manter minha identidade. Elas complementam minha feminilidade, não criam nada. São essenciais para que eu consiga me ver como realmente sou, mas não são indispensáveis. Eu considero que meu gênero está mais ligado à minha psique (Sara).

Ou seja, o vestuário é usado como um signo, um instrumento de manutenção da sua identidade de gênero, que externa o "eu" de Sara (destacado pelo termo "essencialmente"), mas não cria nada que já não exista anteriormente na sua subjetividade, representada em sua fala pelo aspecto psicológico. $\mathrm{O}$ vestir é utilizado como uma ferramenta que auxilia a expressão de sua feminilidade, mas não é o que a torna mulher e nem é parte determinante de sua identidade. A fala de Sara é similar à de Rebeca, estudante universitária de 38 anos que se identifica como mulher transexual:

Sobre a minha relação com roupa, ela vai muito além do objeto de cobrir a nudez, eu vejo a roupa como moda e estilo. A roupa acaba sendo a expressão da identidade de certa forma. "O habito não faz o monge"? Não sei, mas falando de mim, é assim. Eu acho que eu tenho uma relação muito íntima com a roupa feminina. Então pra mim a roupa feminina é a minha expressão de que eu sou uma mulher, logo quero me sentir feminina. Então ela é importante, essa é a relação que eu tenho. Eu não busco moda, etiquetas, assim. Eu gosto de andar elegante, entendeu? De uma maneira, pode ser básica, pode ser um pouco mais, sabe? Um pouco mais chamativa, sensual, tal. Eu tenho, eu preciso de roupas femininas, porque eu sou mulher, eu tenho necessidade de me vestir bem, gosto de me sentir confortável, de me vestir bem feminina. Essa que é a relação que eu tenho, mas eu acredito que ela faz. Pra uma mulher trans, acredito que ela desempenhe um grande papel. Acho que pra mim, falando de mim, ela desempenha um grande papel na expressão da minha identidade como mulher, né (Rebeca).

Em sua fala, adaptada para o título desse artigo, Rebeca novamente reafirma a expressão de sua identidade enquanto mulher por meio das roupas, sendo específica ao citar que isso independe do estilo utilizado. Mas essa expressão passa pelo uso de vestuário que seja também entendido como feminino, como uma forma de reafirmação identitária, que não desafia as normas vigentes. Conforme Judith Butler, o gênero se expressa por meio da performatividade, que seria sempre uma reafirmação de uma norma ou um conjunto de normas (Butler, 2000). Quando fala em normas, está justamente se referindo aos construtos sociais ligados ao gênero. Ela entende que a identidade de gênero é uma estrutura performativa (Butler, 2004) e relacio- 
na-se diretamente com a experiência corpórea. Em uma referência direta a Joan Scott (1995), afirma que "Embora os cientistas sociais se refiram ao gênero como um 'fator' ou 'dimensão da análise', ele também é aplicado a pessoas reais como uma 'marca' de diferença biológica, linguística e/ ou cultural” (Butler, 2003: 28). Essa marca linguística viria dos discursos correntes, uma vez que a diferença sexual é demarcada por intermédio deles, mas não são eles que a causam. A partir do momento em que uma regra ou norma é criada, ela materializa o gênero por meio da reiteração dela mesma.

A elegância e a sensualidade, atributos destacados por Rebeca, passam pelo usar roupas (entendidas como) femininas, uma vez que é mulher. Por esse motivo é possível afirmar que, de certa forma, a generificação do vestuário também auxilia a passabilidade. ${ }^{9}$ Para Thomas, a "roupa ajuda a confundir". Leonardo vai além:

Quando eu me visto, né, assim, as pessoas, elas pensam... Elas não pensam que eu sou uma menina, andando
assim no dia a dia. Tanto que eu tô aqui no shopping e por enquanto não tem ninguém olhando, né. Se eu
me levantar e for comprar alguma coisa, não vai ficar ninguém olhando. As pessoas pensam assim "ah, é um
rapaz", no máximo pensam que eu sou bem mais novo. Aí pela voz elas ficam na dúvida, mas no máximo
acontece de achar que é gay. Se eu não tiver que mostrar a identidade, então... então assim, pela questão da
roupa, entendeu? Por exemplo, como eu me visto, ela não deixa dúvida de que eu sou homem. Eu não uso
mais roupa feminina. [...] Pois é, corte de cabelo, às vezes a roupa, entendeu? E tu acaba adquirindo essa
passabilidade. Que pra gente é até mais fácil de conseguir que pras meninas. Porque assim, as mulheres já
tão acostumadas com homens que tem traços mais delicados. Mas os homens [acostumarem] com traços
masculinos [em mulheres] é um pouco mais complicado. Então elas não têm a passabilidade. Às vezes até
demoram pra adquirir essa passabilidade que a gente já tem. Então quando a gente vai comprar roupa, no dia
a dia é mais fácil, é mais aceitável, é mais tranquilo. É bem de boa, assim. Banheiro, eu até entro no banheiro
masculino, eu não entro é no mictório, né. Mas tipo nenhum homem fica olhando e nem fica assim tipo "será
que é...”. Não, eu entro no banheiro masculino (Leonardo).

Sua fala reforça a ideia de que o vestuário, aliado a outros elementos, como o corte de cabelo, mas também "os traços", seria facilmente interpretado pelos demais, ajudando no entendimento a respeito de si e de sua identidade de gênero. De acordo com Lauretis, o gênero, assim como a sexualidade, não é originado em algo pré-existente nos corpos humanos, mas é, sim, o conjunto de resultados produzidos sobre esses corpos, sobre comportamentos e sobre relações sociais. Por isso, ela o trata como uma tecnologia política, originada de forma tecnosocial e biomédica (Lauretis, 1987: 3). Para ela, a própria representação do gênero é que o ajuda a se construir. Pode-se dizer, baseado nisso, que o gênero consiste em representação e auto-representação, composto por meio de diversas tecnologias, sejam discursivas ou de ordem prática. Por isso, pensando na conjunção de fatores responsáveis pela criação do gênero, a moda, enquanto prática cotidiana, pode ser entendida como uma tecnologia de gênero, produzindo-o e desconstruindo-o.

Enquanto Leonardo busca a compreensão dos demais a respeito de sua identidade de gênero, uma das maiores preocupações de Sara é "chamar atenção de quem não deveria". Nesse sentido, pelo fato de ter ingerido hormônios femininos, acredita estar "perdendo muitas características masculinas" e que, por isso, pessoas, até mesmo em seu local de trabalho poderiam perceber a prática do crossdressing, o que motivou a sua mais recente purge. Essa preocupação se estende para a vida familiar, uma vez que mora com membros de sua família que não sabem de suas práticas. Mesmo assim, a prática segue e quando mencionei a negação de identidade de gênero que muitas mulheres transgênero, crossdressers e travestis passam, ela refletiu:

9 Passabilidade é a capacidade de se fazer vista ou visto de acordo com o gênero com o qual se identifica. 
A busca pelo visual feminino é intensa e causa muita dor. Exatamente porque a sociedade, desde sua própria família, nega essa feminilidade. A roupa é a primeira busca... mas não é a única. Porque a pessoa passa a pensar em sua feminilidade como uma doença. Como um cancro. E passa a culpar os outros por todas as mazelas da vida. E busca a solução para o sentimento de rejeição criando uma barreira enorme com o próprio núcleo social em que vive (Sara).

Sara confirma que a busca pela aparência feminina, seja por meio da roupa ou de outras intervenções, é uma primeira preocupação ao externar a identidade de gênero, mas que toda a experiência é mais complexa que esse primeiro momento. Perguntei como foi a experiência de infância em relação ao ideário de ser entendido como menino e querer roupas de menina. Esse foi o seu relato de como começou a experimentar as roupas entendidas como femininas:

Que eu me lembre a primeira vez que usei as roupas da minha irmã eu tinha uns 8 anos de idade. Eu achava o máximo porque as roupas dela sempre ficaram bem em mim... Como eu te falei nossa diferença de idade é pequena. Mas eu só usava as roupas dela até os $14 \ldots$ Depois passei a usar apenas roupas de menino. Até os 18 , quando conheci meu primeiro namorado. Ele morava sozinho e passei a ir para a casa dele todos os dias. Ele me dava roupas de presente... e eu amava o gosto dele. Ele descobriu que amava minissaias e passou a comprar muitas. No guarda-roupas dele dividíamos espaço para nossas roupas. Eu era magra e era fácil escolher roupas para mim. Ele ficava prestando atenção nas roupas que eu ficava olhando quando passávamos em frente alguma loja. Aí alguns dias depois ele comprava aquela roupa para mim... Quando eu ia sozinha nas lojas, ficava com um pouco mais de coragem e pedia para experimentar, algumas vendedoras não ligavam, mas outras não permitiam e eu ficava frustrada e nunca mais ia naquela loja (Sara).

Foi a relação com esse namorado do passado que fez com que Sara se sentisse à vontade para se montar com mais frequência. Embora escondendo de seus familiares e entre urges e purges, afirma que usou somente roupas femininas em duas épocas de sua vida e que estava muito feliz nesses momentos. Hoje em dia, por motivos profissionais, precisa manter uma "vida social masculina”, segundo ela, e as saídas em público montada são muito restritas. Ela considera que as roupas masculinas a ajudam a ser aceita nos lugares frequentados por pessoas que já a conhecem quando desmontada.

\section{CONFLITOS ENTRE GÊNERO E MODA}

Em se tratando especificamente dos homens transgênero, existe uma preocupação em relação aos seios. São eles que são, por vezes, vislumbrados por sob as roupas e atrapalham a codificação de sua masculinidade. Por isso, caso não os tenham removido por meio de mastectomia, fazem uso de uma espécie de colete, chamado binder, que os comprime, deixando o tórax visualmente plano. De acordo com Thomas, é como "um top grande que pressiona os seios. Eu não consigo usar o binder porque eu não consigo respirar, dá falta de ar, aí eu tô usando top", esclarecendo que sente desconforto porque ele é muito apertado.

Sara relatou que não se sente mais tão confortável frequentando lojas, pois fica um longo tempo olhando e pegando roupas e bijuterias, imagina-se vestindo, mas, ao pensar em experimentar, tem a impressão que a atendente estranharia. Por isso só experimenta quando é uma loja em que já comprou antes. Comentei que mesmo essas lojas em que ela já experimentou tiveram que ser frequentadas uma primeira vez. Concordou, mas disse que "ultimamente tenho ficado bem arredia, diferente de como era antes. Antes eu não me importava muito e se tivesse de experimentar, eu perguntava se podia. Hoje penso muitas vezes antes de pedir”, reforçando que não se sente mais à vontade nesses ambientes. Perguntei se era pela presença das vendedo- 
ras que ficava desconfortável. Respondeu que algumas já foram grosseiras, mas entende que isso acontece por recomendação de superiores e que o que incomoda agora é a exposição. Thomas, por sua vez, relata o desconforto em relação ao uso do uniforme na escola quando era criança:

Quando eu era criança eu não era que nem ele [refere-se a Leonardo], que já sabia desde sempre. Eu sempre gostei de ficar que nem um moleque, tipo jogando bola, sem camiseta. Até os sete anos, que não tinha seio nem nada e não tinha, assim, uma... como é que diz... uma educação castradora por questão dos pais.... Fui criado com os avós até os sete anos, então meus avós me mimavam, né. Me deixavam fazer tudo e meu vô ia pra fazenda e tal e eu usava disso pra eu ficar vestido como eu queria: calça, bota, blusa de botão. Então eu passava a minha vida inteira com meu avô na fazenda, em cima do lombo do cavalo e etc. E no colégio, eu não gostava de usar a farda do colégio, porque tinha a farda feminina e a farda masculina. E eu ia de pijama. [A farda] feminina tinha uma sainha e uma blusa e a masculina era uma bermudinha e uma blusa. Eu ia de pijama, um macacãozinho inteiro, de estrelinha ainda. Aí todo dia vinha anotação na minha agenda: "mãe, fulana quer vim... colocar o uniforme. Continua vindo de pijama. Chamar a atenção". E tipo minha agenda era cheia dessas chamadas [...]. Fiquei com a mesma professora até a segunda série. Fui do jardim até a segunda série. A única que se dispôs a cuidar, me ensinar e me alfabetizar. E eu ia de pijama e toda festinha que tinha, festa junina etc. e de dança, eu queria ser o cara da parada, queria usar sapatos bem lustrados, calça folgada, blusa de botão. Tipo, toda oportunidade que eu tive de usar roupa masculina, eu usava. E aí começou o castramento, né, pelos meus pais. Minha mãe começou a querer que eu usasse vestido, sapato feminino e etc. E eu acabei cedendo pra ela, pra não dar o desgosto pra ela, como ela me falava, né. Então por um tempo eu vivi depressivo, assim, só pra ser aceito pela família, pra não ser marginalizado pela família. E fiquei assim até meus vinte e tantos anos (Thomas).

No caso de Thomas, já em idade pré-escolar demonstrou sua insatisfação com o uniforme escolar, sendo pouco compreendido pelas professoras. A solução para burlar a generificação do traje foi vestir pijamas, que podem ser entendidos como vestimentas neutras nesse contexto, ainda que não aceitas nas regras da escola. Esses pontos são similares ao relato de Marcella.

Já na pré-escola eu sabia que havia algo errado, as professoras me puniam pelo meu comportamento inadequado como usar as meias do uniforme como as meninas e ficar com as meninas pra brincar, certa vez a freira me colocou de joelhoscom uma bíblia em cada mão, e me fez dizer "desculpa, Deus, eu sou menino, não sou menina". A partir daí eu entendi que era "errado" e comecei a imitar os meninos e esconder minha personalidade . Foi muito torturante, mas com 30 anos eu não suportei mais, tentei me matar 18 vezes. Como não consegui, depois que me pai morreu, eu assumi meu verdadeiro gênero para minha família. Foi muito difícil, muitas brigas, mas depois de um ano mais ou menos acabaram aceitando. Os meninos usavam as meias abertas, ou seja, até a panturrilha, mas meninas enrolavam elas até os tornozelos, coisa que eu imitava. Mas sempre vinha uma professora e puxava minhas meias pra cima e reclamava (Marcella).

A escola tem forte papel de controle e normalização dos sujeitos, pois trata de criar indivíduos adequados às regras implícitas e explícitas da sociedade, ou, então, isolá-los do convívio com os demais. É na escola que começam as primeiras socializações das crianças, mas é lá, também, que elas são submetidas às primeiras regras a respeito de si e do mundo. Entre essas regras, aparecem aquelas relacionadas ao gênero e ao comportamento. Conforme Simone Ávila:

Práticas escolares como uniformes diferentes para meninas e meninos, divisão entre meninos e meninas nas filas, banheiros masculinos e femininos, etc., ainda se fazem presentes em muitas escolas e ensinam de modo nem tão explícito, o que é ser "normal", e como você tem de ser ou se comportar para ser aceito/a socialmente (Ávila, 2014: 114).

A família aparece como uma entidade que regula, assim como a escola, o seu desejo de livre expressão de identidade de gênero. Carla, de gênero não-binário, estudante de 19 anos, tem dificuldades de relacionamento com a mãe, uma vez que essa não parece entender plenamente sua identidade de gênero. Por isso precisou entabular uma conversa sobre seu não-binarismo. 
Por mais que minha mãe tivesse relutância, por saber que as roupas que eu escolhia eram muito mais que estilo mas representavam uma identidade de gênero que ela não estava acostumada. Ela preferia que eu fosse mais uma "garota" com estilo tradicionalmente masculino/andrógino do que uma pessoa trans (Carla).

No caso de Carla, sua mãe tenta compreender sua identidade, porque é o desconhecimento que cria a tensão dentro do lar. Sendo uma pessoa bastante nova, representa uma geração de pessoas transgênero que, apesar de certos desentendimentos, não são expulsas de casa e tentam contornar os problemas com o diálogo e a informação. Tiago Duque já havia sinalizado essa nova realidade entre as travestis adolescentes que foram interlocutoras de sua pesquisa e que, apesar da violência encontrada nas ruas e mesmo dentro de casa, "não tem rompido os laços com seus familiares" (Duque, 2012, p.185).

Lucas, técnico em enfermagem que afirma ter deixado de ser travesti, também passou por desentendimentos com a família e chegou a sair de casa. Quando voltou, já como Isadora, nome pelo qual atendia, a mãe passou a ajudá-la a se montar:

No meu guarda roupa, ou melhor, na minha pequena cômoda de madeira, onde ficava minhas roupas, já não havia mais nenhum rastro de roupas de rapaz. Tudo era da Isadora, um nome que eu me identificava. Vestidos, bolsas, tudo que possa imaginar, até minha mãe que era contra passou a escolher minhas roupas. Começou a comprar roupa para mim, me transformar numa filha, com um estilo bacana, que ninguém me julgasse pelo que sou: vestidos longos, saias, calças, eu aceitava os conselhos dela. Pois ela sempre dizia que o travesti é como uma mulher, se não se der valor homem nenhum quer (Lucas).

Havia uma preocupação por parte da mãe de Isadora de vesti-la de forma a ser melhor assimilada pela sociedade. Para isso, fazia-se uso do "estilo" citado por Miller (2013), que nesse caso, deveria se enquadrar em padrões tradicionais de feminilidade, tanto no que diz respeito ao trajar quanto ao agir. À feminilidade foi negada o valor intrínseco: a pessoa que a experiencia precisa dar-se esse valor e validação, que, nesse caso, viria do desejo masculino.

Embora muitas peças do vestuário tenham sido incorporadas no vestir de mais de um gênero, tal fato ocorreu mais facilmente com roupas entendidas como masculinas usadas por mulheres do que o oposto. A marcação de gênero em relação às roupas ainda é forte. Além disso, mesmo que muitas peças tenham se tornado de uso comum no guarda-roupa de diversos gêneros, ainda assim há marcadores específicos que sinalizam sua adequação. Em Sapos e Princesas, sua etnografia a respeito das praticantes de crossdressing, Anna Paula Vencato questiona a fala de suas interlocutoras, que afirmam que mulheres praticando crossdressing e mesmo drag kings não são interessantes, já que as mulheres podem usar roupas masculinas sem que haja nenhum tipo de estigma.

É interessante pensar que ao dizer que uma mulher pode usar calças e ninguém fala nada não se preste atenção ao fato de que não é qualquer boné, calça e tênis que podem, de fato, ser usados por mulheres, assim como não é possível para qualquer mulher, com qualquer corporalidade ou performance de gênero, fazer uso de roupas e acessórios femininos e ser socialmente aceita (Vencato, 2013: 168).

A autora estabelece que mesmo que haja uma maior aceitação desse trânsito de signos quando feito por mulheres, ainda assim existem certos códigos de vestimenta e de conduta que marcam a aceitação. As repetidas falas trazidas por interlocutoras e interlocutores até aqui transparecem a preocupação de utilizar determinados tipos de vestir visando essa procurada aceitação. Quando perguntei para Carla a respeito do desejo que afirmava ter quando criança de poder alternar a sua identidade de gênero entre masculina e feminina e como seus pais rea- 
giam, respondeu de forma a demonstrar o papel de marcação do gênero que a moda, aliada ao discurso, possui:

Meu pai nunca ligou muito sobre minha identidade ou a forma que me vestia. Minha mãe por outro lado, sempre foi bem ativa nisso. Ela sempre comprava roupas tradicionalmente femininas, saias, coisas rosas, por mais que eu nunca tenha gostado desse tipo de roupa. Ela também sempre me tratava por apelidos como "menininha", "garotinha", "florzinha". Não lembro de em algum momento da minha vida ter me sentido bem com esses apelidos e lá pelos meus 13/14 anos ela parou porque percebeu que eu não gostava desse tratamento. Meu pai mora longe, então ele não sabe de nada, mas suspeita (da minha sexualidade, não do meu gênero). Deixei meu não binarismo bem claro para minha mãe quando tinha 17 anos, mas ela nunca entendeu direito e acha que quero "ser homem". [...] Até ano passado eu tinha um estilo mais "masculino". Cabelo bem curto, camisa social e sutiã esportivo para diminuir o tamanho dos seios. Esse ano estou mais "feminina", mas continuo usando as roupas de antes uma vez ou outra (Carla).

Nesse caso a feminilidade era marcada por sua mãe no delicado e no diminuto e a identidade de gênero não-binária não é completamente compreendida por ela. Quando perguntei se considerava neutras as roupas que são entendidas como masculinas, já que dava preferência a elas, Carla respondeu:

Só consigo responder partindo de dois pontos de vista, já que gênero pode envolver muito o Eu com a relação com os outros (por exemplo, a aceitação social da minha identidade de gênero). Bom, pessoalmente, num nível particular, considero qualquer roupa que uso neutra, mas sei que pra outras pessoas não é assim. As únicas vezes que sentia que para os outros a roupa era neutra era quando eu me vestia da forma mais andrógina possível, de resto, tanto as roupas essencialmente masculinas quanto as essencialmente femininas, eu sentia que eram vistas com forte marcação de gênero (Carla).

Ou seja, é na prática de misturar de elementos de moda entendidos como masculinos com outros entendidos como femininos que alcança uma estética que consegue ser lida como neutra. As peças são agenciadas de acordo com a necessidade de expressão vinculada à performatividade de gênero. Perguntei se essa forma de utilizar a moda para se apresentar como gênero não-binário tinha, então, mais a ver com a percepção dos demais do que com a maneira como vê suas roupas e Carla respondeu:

A minha percepção das roupas também é importante. É a partir da minha visão de que para mim todas as roupas podem ser neutras que tento mudar a sociedade ao meu redor e tento desmontar essa ideia fixa de que saia=mulher ou terno=homem. Para muitas pessoas a marcação de gênero nas roupas que elas usam é importante e tudo bem, mas como eu disse, isso não pode ser uma ideia fixa, a neutralidade das roupas também deve ser respeitada (Carla).

Carla parte da desconstrução da ideia de roupas como marcadores de gênero. As peças não só são unissex como não-binárias, ou, melhor ainda, neutras. Para Leonardo, a roupa não tem gênero, mas ela expressa o gênero no contexto da sociedade e isso pode ser negativo porque, segundo seu exemplo, uma menina que vista "cueca ou roupas masculinas", porque gosta do estilo ou se sente mais confortável assim, vai ser lida como "lésbica masculina" ou "homem transgênero". Ainda para ele, essa é uma leitura da sociedade, que acaba por nos informar que na prática a roupa tem gênero.

Essa realidade reflete-se facilmente na hora de comprar roupas, especialmente porque modelagens e tamanhos não são iguais para roupas masculinas e femininas. Thomas reclama que as calças masculinas são muito retas e por isso não vestem bem. Leonardo concorda e diz que elas marcam e deixam o quadril maior. Por isso, o primeiro compra calças femininas e o segundo dá preferência para bermudas e as utiliza com camisas masculinas para obter a apa- 
rência desejada. Sapatos masculinos, por sua vez, tem uma numeração que começa geralmente no número 38. Como Thomas usa 36, precisa comprar sapatos infantis ou maiores que seu pé. Rebeca tem o mesmo problema, mas porque calça 42 e raramente encontra sapatos femininos com essa numeração.

De todo modo, nem sempre a experiência de comprar em lojas é fácil. Leonardo só compra roupas pela internet, para facilitar o processo. Thomas afirma que vai a lojas de departamento junto com a namorada, que o ajuda a escolher as peças. Ele tem receio de estar sendo observado e não se sente seguro para ir só. Também usa o provador feminino, porque tem medo de sofrer transfobia nesse processo.

\section{CONSIDERAÇÕES FINAIS}

As narrativas em torno da experiência transgênero obtidas nesta pesquisa são múltiplas e não proponho que sejam entendidas como uma mostra de uma visão monolítica de um grupo tão variado de pessoas. O que elas têm em comum, ainda que de maneira diversa, é o fato de que a formação da subjetividade perpassa a relação entre corpo, performatividade, identidade de gênero e moda. Essa conexão entre categorias se estabelece de maneira clara.

A moda, em específico, utilizada no vestir dos sujeitos, ao lado de outras ferramentas performativas, propaga significados já conhecidos. Seja por meio de roupas, de acessórios ou mesmo do próprio corpo, ela expressa a noção de individualidade, marcada pelas subjetividades. Por outro lado, evidencia o pertencimento coletivo, especialmente no que diz respeito à conformidade ao que é entendido como feminino ou como masculino, adequando sujeitos a grupos divididos de acordo com a identidade de gênero. Por isso é citada como elemento de grande importância quando se trata da passabilidade e ainda precisa ser desafiada no sentido de trazer neutralidade.

Mas apesar das funções marcadas no que diz respeito tanto à individualidade quanto ao senso de grupo, interlocutoras e interlocutores esclarecem que, para eles, a moda não cria nada que já não seja pré-existente. Por isso, é adequadamente reforçado que "a roupa expressa a identidade", externando aspectos subjetivos ou ainda tornando a superfície deles mais clara. Práticas sobre o uso da moda e discursos a esse respeito aparecem como capazes de criar representações, na forma de imagem, autoimagem e regulações. Por meio da moda, o trânsito por determinados espaços é facilitado. Como tecnologia de gênero que é, ela cria um corpo, codifica identidades, transmite valores específicos de feminilidades e masculinidades e traz à tona a expressão subjetiva das experiências.

\section{BIBLIOGRAFIA}

Ávila, Simone. 2014. Transmasculinidades: A emergência de novas identidades politicas e sociais. Rio de Janeiro: Plural. 
Bento, Berenice. 2004. “Transexualidade oficial às transexualidades”. Pp.143-171 em Sexualidade e Saberes: Convençôes e Fronteiras, organizado por A. Piscitelli; M. F. Gregori; S. Carrara. Rio de Janeiro: Editora Garamond.

2006. A reinvenção do corpo: sexualidade e gênero na experiência transexual. Rio de Janeiro: Garamond. 2009. A diferença que faz a diferença. Bagoas 4: 95-112.

Blumer, Herbert. 2005. "Fashion: from class differentiation to collective selection". The sociological quarterly 10(3): 275-291.

Bovone, Laura. 2006. Urban style cultures and urban cultural production in Milan: Postmodern identity and the transformation of fashion. Science Direct 34(6): 370-382.

Butler, Judith. 2000. "Corpos que pesam: Sobre os limites discursivos do Sexo". Em: O Corpo Educado: pedagogias da sexualidade, organizado por G. Lopes. Belo Horizonte: Autêntica. . 2003. Problemas de gênero: feminismo e subversão da identidade. Rio de Janeiro: Civilização Brasileira. 2004. Undoing Gender. New York: Routledge.

Crenshaw, Kimberlé. 2002. "Documento para o encontro de especialistas em aspectos da discriminação racial relativos ao gênero". Estudos Feministas 10(1): 171-188.

Crane, Diana, Bovone, Laura. 2006. Approaches do material culture: The sociology of fashion and clothing. Science Direct 34(6): 319-333.

Duque, Tiago. 2012. Da finada à europeia: experiências de ser, não permanecer e estar travesti na adolescência. Bagoas 7: 173-198.

Eco, Umberto. 1989. "O hábito fala pelo monge" em Psicologia do Vestir, por U. Eco et all. Lisboa: Assírio e Alvim.

Lauretis, Teresa de. 1987. Technologies of Gender: Essays on theory, film and fiction. Indianapolis: Indiana University Press.

Lipovetsky, Gilles. 2009. O Império do Efêmero: a moda e seu destino nas sociedades modernas. São Paulo: Companhia das Letras.

Maluf, Sonia Weidner. 2001. "Corpo e corporalidade nas culturas contemporâneas: abordagens antropológicas”. Esboços 9(9): 87-101.

. 2002. "Corporalidade e desejo: Tudo sobre minha mãe e o gênero na margem". Revista Estudos Feministas 10(1): 143-153.

2007. "Políticas e teorias do sujeito no feminismo contemporâneo" em Novos Olhares, Muitos Lugares, organizado por C. B. Silva; G. O. Assis, G. Oliveira; R. C. Kamita. Florianópolis: Editora Mulheres.

Miller, Daniel. 2013. Trecos, troços e coisas. Rio de Janeiro: Zahar.

Parreiras, Carolina. 2009. "Fora do armário... dentro da tela: Nota sobre avatares, (homo) sexualidades e erotismo a partir de uma comunidade virtual” Pp. 343-372 em Prazeres dissidentes, organizado por M.E. Díaz-Benitez; C.E.Fígaro. Rio de Janeiro: Garamond.

Portela, Andrea; Brandão, Ludmila. 2008. "Corpos metamórficos para vestir” Pp. 61-66 em Gênero e Tecnologias, Tecnologias de Gênero: estudos, pesquisas e poéticas interdisciplinares, organizado por D. GALINDO; L. L. Cuiabá: EDUFMT.

Santos, Jocélio Teles dos. 1997. "Incorrigíveis, afeminados, desenfreados: indumentária e travestismo na Bahia do século XIX”. Revista de Antropologia 40(2): 145-182.

Scott, Joan Wallach. 1995. Gênero: uma categoria útil de análise histórica. Educação E̊ Realidade 20(2): 71-99.

. "Experiencia”. 2001. La Ventana 13: 42-73. 
Sellerberg, Ann-Mari. 2001. "Sociology of Fashion” Pp 5411-5415 em International Encyclopedia of Social E Behavioral Sciences v.8, editado por N. J. Smelser; P. B. Baltes. Amsterdã: Elsevier.

Simmel, Georg. 2008. “A Moda”. Iara 1(1): 163-188.

Svendsen, Lars. 2010. Moda: Uma filosofia. Rio de Janeiro: Zahar.

Vencato, Anna Paula. 2003. "Confusões e estereótipos: o ocultamento de diferenças na ênfase de semelhanças entre transgêneros". Cadernos AEL 10(18-19): 187-215. . 2005 "Fora do armário, dentro do closet: o camarim como espaço de transformação". Cadernos Pagu 24: 227-247.

2013. Sapos e princesas: prazer e segredo entre praticantes de crossdressing no Brasil. São Paulo: Annablume.

\section{CLOTHING EXPRESSES IDENTITY: FASHION AS A GeNDER TECHNOLOGY IN THE TRANSGENDER EXPERIENCE}

This article explores fashion as a technology of gender, and its capability of creating gender through discourses or practices. By reviewing transgender experiences, the author discusses how clothes encode meanings and convey the expression of femininities and masculinities. On the other hand, the article questions the very notion of what would be feminine or a masculine fashion objects, as those are used according to the necessity of expression of subjectivities, negotiating bodies and identities. The author presents the perceived conflicts between these subjectivities and the norms that involve clothing, especially when it comes to family and school, two outstanding normalization agents. It is emphasized that narratives, in their plurality, should not be read as a monolithic expression of the transgender experience, but as a sample of the relation between performativity and fashion.

Keywords: transgender, gender technology, fashion, performativity

Date received: 2018-07-31

Date accepted: 2019-02-20 